\title{
Spatio-Temporal Dynamics of Land Use/Cover around a Thermal Power Plant in Singrauli District, Madhya Pradesh, India
}

\author{
Maya Kumari*1\&2 and Kiranmay Sarma ${ }^{1}$ \\ ${ }^{1}$ School of Environmental Management, Block 'A' Guru Gobind Singh Indraprastha University, New Delhi, \\ India \\ ${ }^{2}$ Amity School of Natural Resources \& Sustainable Development, Amity University, Noida, Uttar Pradesh. India
}

\begin{abstract}
Land is becoming a scarce resource due to population growth and industrialization. Rapid growth of human activities can also be attributed as one of the reasons. Thus, it becomes an important task to regulate land resource for sustainable development and environmental protection. Land use/cover (LULC) change studies have become a central component in current strategies for managing natural resources and monitoring environmental changes. The present study the land use/cover and its pattern was studied for the Sasan Ultra mega thermal power plant covering an area of $10 \mathrm{~km}^{2}$ for three years $(2005,2010$ and 2015) respectively. Chronologically, the year 2005 is the phase of pre-establishment of the thermal power plant; the year 2010 specifies the construction phase and 2015 is the operational phase. Landsat ETM and Landsat 8 data of remote sensing system were used for the study. The land use/cover (LULC) study showed a significant decrease in forest cover, while vegetation and wasteland expanded dramatically. Simultaneously, there is a decrease in Barren rocky land from 2005 to 2015.
\end{abstract}

Keywords: Land use; spatio-temporal change; supervised classification; accuracy assessment; kappa statistics.

\section{Introduction}

Land resource is one the most important natural resources that possibly will play a dynamic role in the life of not only mankind, but also the entire assemblage of all living beings. Interaction of human with environment influence land use /land cover (LULC) change and thus, it is necessary to monitor changes. One of the driving factors of global environment alteration is. LULC change. During the 1972 Stockholm Conference on the Human Environment the scientific research community urged for applied research on land use changes, and again after 20 years, at the United Nations Conference on Environment and Development (UNCED) in 1992. Meanwhile, International Geosphere and Biosphere Programme (IGBP) and International Human Dimension Programme (IHDP) co organized a working group to establish research agenda and promote research activity on LULC changes.

The land use system is extremely dynamic and usually would undergo effective changes based on the changing socio-economic and natural environment. The change in any form of land use largely depends on the human intervention and the pressure build up within the system (Bisht and Kothyari, 2001). Changes may involve the nature or intensity of change but may also include spatial and time aspects. The pace, magnitude and spatial influence of human changes of the Earth's land surface are unprecedented. Landuse/cover changes are so ubiquitous that, when aggregated globally, they significantly affect key aspects of Earth System functioning. Such changes also determine, in part, the vulnerability of places and people to climatic, economic socio-political unrests. The continuous change of land use in these days, been recognized to bring dangerous environmental degradation to both natural ecosystems, such as forest ecosystems (Alanso Peez et al, 2003), and reverine ecosystems (Yunus et al, 2003) and manmade ecosystems (Lopez et al, 2001).

With advent of remotely sensed data made possible to study the spatio-temporal land cover in less time, in a cost-effective way and with better accuracy (Kachhwaha, 1985) in association with Geographical Information System (GIS) that provide suitable platform for data analysis, update and retrieval (Star et al, 1997 and Chilar, 2000). Space-borne remote sensing data may be particularly useful in developing countries where recent and reliable spatial information is lacking (Dong et al, 1997). Remote sensing technology and geographic information system (GIS) provide effective methods for analysis of land use issues and tools for land use planning and modeling. By understanding the driving forces of land use development in the past, managing the current situation with modern GIS tools, and modeling the future, one can develop plans for multiple uses of natural resources and nature conservation. The change in any form of land use is largely related either with the external forces and the pressure built-up within the system (Bisht and Kothyari, 2001). The collection of remotely sensed data facilitates the synoptic analyses of Earth - system function, patterning, and change at 
Spatio-Temporal Dynamics of Land Use/Cover around a Thermal Power Plant in Singrauli ..

local, regional and global scales over time; such data also provide an important link between intensive, localized ecological research and regional, national and international conservation and management of biological diversity (Wilkie and Finn, 1996).

Therefore, attempt was made to study the status of land use land cover around $10 \mathrm{Km}^{2}$ area of Sasan Ultra mega thermal power plant temporally with a view of detecting the changes that has taken place.

\subsection{Study Area}

\section{Data And Methods}

Singrauli is the 50th district of the state of Madhya Pradesh in India. The status of a district was given to it on 24May 2008, with its headquarters at Waidhan. It was formed after dividing it from Sidhi district.

Singrauli has three tehsils namely Singrauli, Deosar and Chitrangi. Singrauli town is a Municipal Corporation with a population of about two lakhs. The population of Singrauli district is about 11 lakhs (1.1 million).

The present study area falls in the eastern part of the state of Madhya Pradesh along with the adjoining southern part of Sonebhadra district of Uttar Pradesh together constitute Singrauli, formerly also called Shringavali. Dense and unnavigable forests covered the entire district and wild animals inhabited the area. Today, itis fast emerging as the energy hub of India and Singrauli is emerging as India's new energy capital. The total installed capacity of all thermal power plants at Singrauli is around 10\% of total installed capacity of India. The locals also call it as 'Urjanchal' i.e. the land of energy

At present, 17 big power projects have already started their work of setting up big plants and industries in various parts of Singrauli district resulting in a large-scale displacement of land and property. One of the power plants is Sasan ultra mega power plant (Sasan UMPP). The power plant is located near village Sasan in Singrauli (earlier Sidhi) district of Madhya Pradesh State. The site is near to the Govind Ballabh Pant Sagar, and gets its water supply from this reservoir. Captive coal mines provide enhanced reliability of fuel supply. Sasan UMPP has a capacity of 3960 MW. Generated electricity is supplied to fourteen distribution companies in seven states namely Madhya Pradesh, Uttar Pradesh, Delhi, Rajasthan, Punjab, Haryana, Uttarakhand with total population of about 35 Crores.

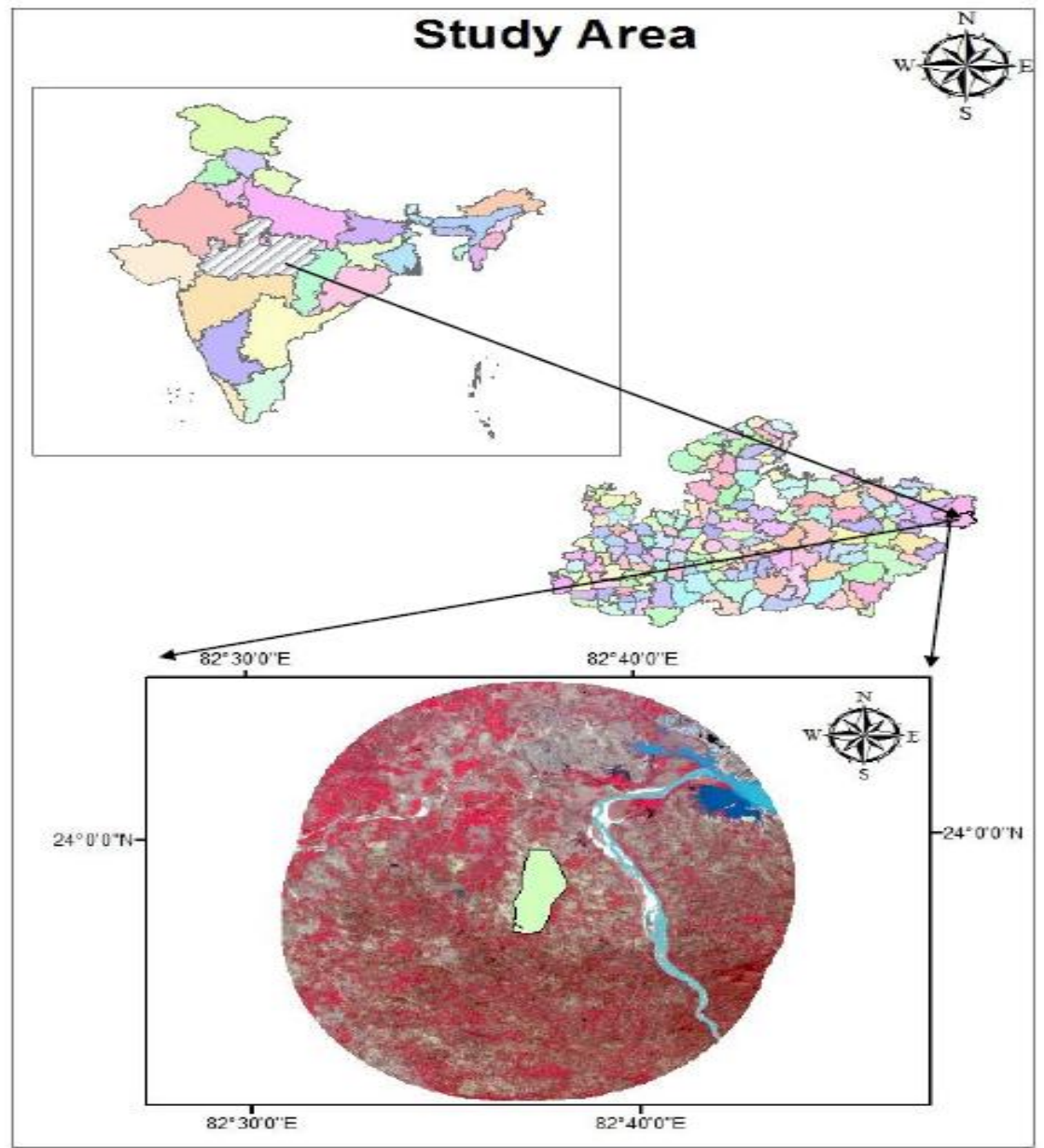

Fig. 1: Map of study area, Singrauli, India 
The baseline land use/cover and vegetation - land surface temperature relationship of the study area of $10 \mathrm{~km}$ radius from the project site is identified through buffering method.

\subsection{Satellite imagery pre-processing}

The Landsat 7 ETM images acquired in February 2005, 2010 and Landsat 8 in February 2015 serve as the primary data source for deriving Land use/cover and NDVI in the Singrauli urban ecosystem. Since, both Landsat ETM and Landsat 8 images were captured under clear conditions ( $0 \%$ cloud coverage for both images), uniform atmospheric conditions within the images are assumed and therefore, no atmospheric corrections are applied.

All the images were preprocessed by the USGS to rectify any geometric or radiometric distortions in the image.

\subsection{Derivation of Landuse/Cover}

Maximum likelihood technique was used for supervised classification. The maximum likelihood decision rule assigns each pixel having pattern measurements or features $\mathrm{X}$ to the class $\mathrm{c}$ whose units are most probable or likely to have given rise to feature vector $\mathrm{x}$. Maximum likelihood classification considers not only the mean or average values in assigning classification, but also the variability of brightness values in each class. It assumes that the training data statistics for each class in each band are normally distributed, that is, Gaussian. An advantage of this method is that it provides an estimate of overlap areas based on statistics.

A most common and typical method used by researchers to assess classification accuracy is with the use of an error matrix (Card, 1982 and Congalton, 1991). An error matrix is a square assortment of numbers defined in rows and columns that represent the number of sample units (i.e., pixels, clusters of pixels, or polygons) assigned to a particular category relative to the actual category as confirmed on the ground. The rows in the matrix represent the remote sensing derived land use map (i.e., Landsat data), while the columns represent the reference data (i.e., training signatures) (Jensen, 1986). These tables produce many statistical measures of thematic accuracy including overall classification accuracy, percentage of omission and commission error by category, and the Kappa coefficient, an index that relays the classification accuracy after adjustment for chance agreement (Cohen, 1960 and Congalton et al, 1983). Error of omission is the percentage of pixels that should have been put into a given class but were not. Error of commission indicates pixels that were placed in a given class when they actually belong to another. These values are based on a sample of error checking pixels of known land cover that are compared to classifications on the map. Errors of commission and omission can also be expressed in terms of user's accuracy and producer's accuracy. User's accuracy represents the probability that a given pixel will appear on the ground as it is classed), while producer's accuracy represents the percentage of a given class that is correctly identified on the map

\subsection{Spatio Temporal Analysis of LULC}

\section{Results And Discussion}

An elongated patch of dense forest is running south of the site and cover 39.60 percent of the total area. It gets thicker on the western part and around the Govind Ballabh pant Sagar water reservoir. The forest area has sharply declined from the year 2005 to 2015 i.e. from 39.60 percent to 23.49 percent of the total area (Figure 2a, $2 \mathrm{~b}$ and $2 \mathrm{c})$.

The construction activities undergoing around the site can be one of the reason for the decline. Vegetation is a general term for the plant life of a region; it refers to the ground cover provided by plants, and is, by far, the most abundant biotic element of the biosphere. However, the percentage of such land use is limited to 3 percent of the total area in the year 2005. Due to conversion of forest into other land use such as cultivable land and plantation the area of vegetation has increased from the year 2005 to 2015 by 7.51 percent. Huge patches of marshy lands (11.8\%) are observed on the western parts of Govind Ballabh Pant Sagar (Table 1). Ramachandra and Bharath (2012) also revealed that land use change is observed sequent to setting of large scale thermal power plants at Padubidri, Udupi district of Karnataka between 2003 and 2011.The results shows that land cover has gradually changed from dense forest to cleared land to thermal power plant and associated amenities during the study period. Sharp decline in vegetation cover was observed while built-up land has increased during the period. 


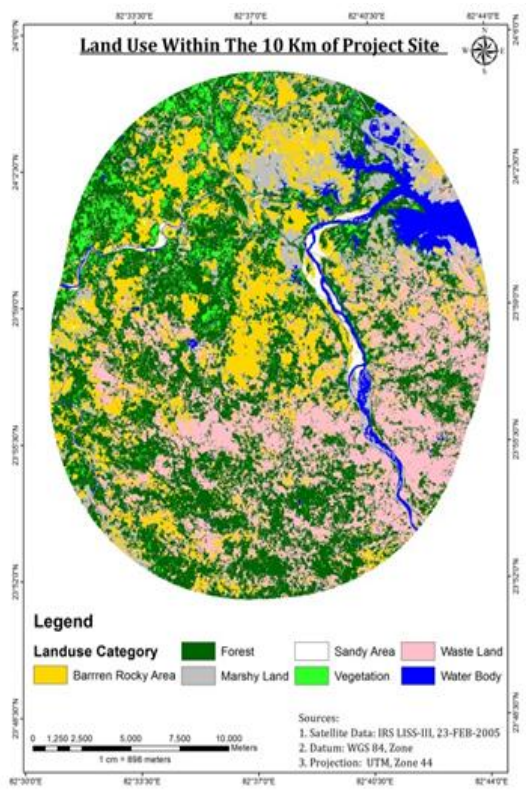

(a)



(b)

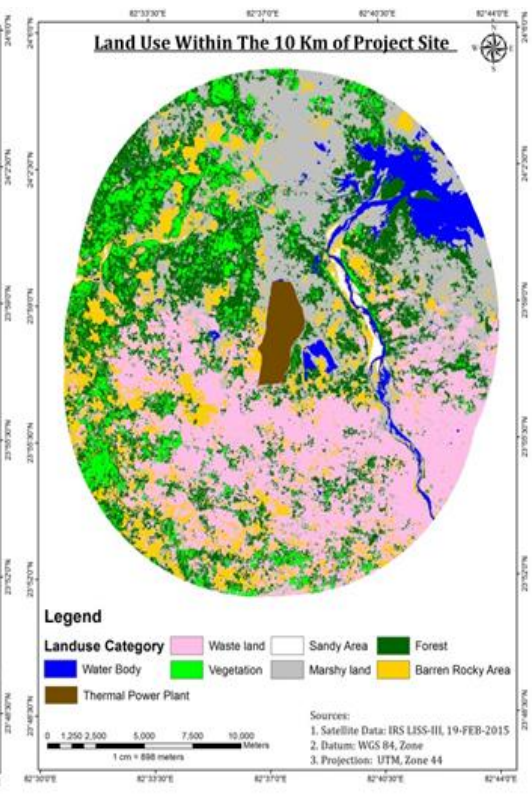

(c)

Figure. 2: Land use/cover (a) 2005 (b) 2010 (c) 2015

Table 1: Spatio-Temporal Land Use/Cover of the Project Site.

\begin{tabular}{|c|c|c|c|c|c|c|}
\hline \multirow{2}{*}{$\begin{array}{l}\text { Name/date } \\
\text { Class }\end{array}$} & \multicolumn{2}{|c|}{ Year February 2005} & \multicolumn{2}{|c|}{ Year February 2010} & \multicolumn{2}{|c|}{ Year February 2015} \\
\hline & Sq. km & Area $(\%)$ & Sq. $\mathbf{k m}$ & Area $(\%)$ & Sq. km & Area $(\%)$ \\
\hline Waterbody & 19.30 & 4.30 & 15.14 & 3.38 & 20.56 & 4.58 \\
\hline Waste Land & 103.77 & 23.14 & 90.66 & 20.22 & 119.39 & 26.62 \\
\hline Vegetation & 13.49 & 3.00 & 17.91 & 3.99 & 33.67 & 7.51 \\
\hline Sandy Area & 4.30 & 0.96 & 5.21 & 1.16 & 1.97 & 0.44 \\
\hline Marshy Land & 53.01 & 11.83 & 79.107 & 17.64 & 111.58 & 24.88 \\
\hline Forest & 177.59 & 39.60 & 175.25 & 39.08 & 105.34 & 23.49 \\
\hline Barren Rocky Area & 76.99 & 17.17 & 65.16 & 14.53 & 48.25 & 10.76 \\
\hline
\end{tabular}

A marsh is a type of wetland, featuring grasses, rushes, reeds, typhas, sedges, cat tails, and other herbaceous plants (possibly with low-growing woody plants) in a context of shallow water. As the constructional and operational activities, has started by 2010 and 2015 respectively the area of marshy land has increased by 24.88 percent in the year 2015. Tharimena et al (2011) studied the environmental impact of thermal power plant at Koradi, Nagpur. The area under study shows increase in water logged area due to discharge from plant and the water-logged surface is seen to be covered with phytoplankton which has increase four times during 2001 and 2009. The reservoir of Govind Ballabh Pant Sagar is one of main features of land use of the study area. Other major rivers in the area are Mayar and Rehar River. There are few static surface water bodies. The total area of water body in the year 2005 is 4.3 percent of the total area. Waterbodies has shown marginal variation in the area in the successive years.

\subsection{Classification Accuracy Assessment}

Quantitatively assessing classification accuracy requires the collection of some in situ data or a priori knowledge about some parts of the terrain, which can then be compared with the remote sensing derived classification map.

Table 2: Classification Accuracy Assessment (Error Matrix)

\begin{tabular}{|l|c|c|c|c|c|c|c|c|c|c|}
\hline & $\begin{array}{c}\text { Water } \\
\text { body }\end{array}$ & Vegetation & Forest & $\begin{array}{c}\text { Sandy } \\
\text { Area }\end{array}$ & $\begin{array}{c}\text { Barren } \\
\text { Rocky } \\
\text { Area }\end{array}$ & $\begin{array}{c}\text { Marshy } \\
\text { Land }\end{array}$ & $\begin{array}{c}\text { Waste } \\
\text { Land }\end{array}$ & $\begin{array}{c}\text { Row } \\
\text { Total }\end{array}$ & $\begin{array}{c}\text { Producer } \\
\text { Accuracy } \\
(\%)\end{array}$ & $\begin{array}{c}\text { User } \\
\text { Accuracy } \\
(\%)\end{array}$ \\
\hline \multicolumn{7}{|c|}{$\mathbf{2 0 0 5}$} \\
\hline Water body & 14 & 0 & 0 & 0 & 0 & 0 & 0 & 14 & 100 & 100 \\
\hline Vegetation & 0 & 10 & 1 & 0 & 0 & 0 & 0 & 11 & 83.33 & 90.91 \\
\hline Forest & 0 & 2 & 141 & 0 & 2 & 0 & 5 & 150 & 97.92 & 94 \\
\hline
\end{tabular}


Spatio-Temporal Dynamics of Land Use/Cover around a Thermal Power Plant in Singrauli ..

\begin{tabular}{|c|c|c|c|c|c|c|c|c|c|c|}
\hline Sandy Area & 0 & 0 & 0 & 0 & 0 & 0 & 0 & 0 & -- & --- \\
\hline $\begin{array}{l}\text { Barren } \\
\text { Rocky Area }\end{array}$ & 0 & 0 & 0 & 0 & 64 & 5 & 2 & 71 & 84.21 & 90.14 \\
\hline $\begin{array}{l}\text { Marshy } \\
\text { Land }\end{array}$ & 0 & 0 & 1 & 0 & 9 & 45 & 0 & 55 & 90 & 81.82 \\
\hline Waste Land & 0 & 0 & 1 & 0 & 1 & 0 & 98 & 100 & 93.33 & 98 \\
\hline $\begin{array}{l}\text { Column } \\
\text { Total }\end{array}$ & 14 & 12 & 144 & 0 & 76 & 50 & 105 & 401 & \multicolumn{2}{|c|}{$\begin{array}{c}\text { Overall Accuracy }= \\
94.20 \%\end{array}$} \\
\hline \multicolumn{11}{|c|}{2010} \\
\hline Water body & 16 & 0 & 0 & 0 & 0 & 0 & 0 & 16 & 88.89 & 100 \\
\hline Vegetation & 0 & 10 & 1 & 0 & 0 & 0 & 0 & 11 & 71.43 & 90.91 \\
\hline Forest & 0 & 4 & 153 & 0 & 1 & 1 & 3 & 162 & 98.08 & 94.44 \\
\hline Sandy Area & 0 & 0 & 0 & 4 & 0 & 0 & 0 & 4 & 100 & 100 \\
\hline $\begin{array}{l}\text { Barren } \\
\text { Rocky Area }\end{array}$ & 2 & 0 & 1 & 0 & 50 & 2 & 1 & 56 & 98.04 & 89.29 \\
\hline $\begin{array}{l}\text { Marshy } \\
\text { Land }\end{array}$ & 0 & 0 & 1 & 0 & 0 & 57 & 5 & 63 & 95 & 90.48 \\
\hline Waste Land & 0 & 0 & 0 & 0 & 0 & 0 & 73 & 73 & 89.02 & 100 \\
\hline $\begin{array}{l}\text { Column } \\
\text { Total }\end{array}$ & 18 & 14 & 156 & 4 & 51 & 60 & 82 & & \multicolumn{2}{|c|}{$\begin{array}{c}\text { Overall Accuracy = } \\
95.60 \%\end{array}$} \\
\hline \multicolumn{11}{|c|}{2015} \\
\hline Water body & 17 & 0 & 0 & 0 & 0 & 0 & 0 & 17 & $85.00 \%$ & $100.00 \%$ \\
\hline Vegetation & 0 & 21 & 2 & 0 & 0 & 0 & 0 & 23 & $95.45 \%$ & $91.30 \%$ \\
\hline Forest & 1 & 1 & 102 & 0 & 0 & 0 & 1 & 105 & $96.23 \%$ & $97.14 \%$ \\
\hline Sandy Area & 0 & 0 & 0 & 6 & 0 & 0 & 0 & 6 & $100.00 \%$ & $100.00 \%$ \\
\hline $\begin{array}{l}\text { Barren } \\
\text { Rocky Area }\end{array}$ & 0 & 0 & 0 & 0 & 44 & 0 & 1 & 45 & $100.00 \%$ & $97.78 \%$ \\
\hline $\begin{array}{l}\text { Marshy } \\
\text { Land }\end{array}$ & 2 & 0 & 1 & 0 & 0 & 75 & 2 & 80 & $100.00 \%$ & $93.75 \%$ \\
\hline Waste Land & 0 & 0 & 1 & 0 & 0 & 0 & 127 & 128 & $96.95 \%$ & $99.22 \%$ \\
\hline $\begin{array}{l}\text { Column } \\
\text { Total } \\
\end{array}$ & 20 & 22 & 106 & 6 & 44 & 75 & 131 & & \multicolumn{2}{|c|}{$\begin{array}{c}\text { Overall Accuracy }= \\
97.60 \%\end{array}$} \\
\hline
\end{tabular}

The error matrix in the table indicates an overall accuracy of $94.20 \%, 95.60 \%, 97.60 \%$ in year 2005 , 2010 and 2015 respectively (Table 2). However, producers' accuracy ranged from $83.33 \%$ (Vegetation) to $100 \%$ (water body) and users' accuracy ranged from $81.82 \%$ (marshy land) to $100 \%$ (water body) in the year 2005. In the year 2010 producers' accuracy range from $71.43 \%$ (Vegetation) to $100 \%$ (water body, sandy area and waste land) and users' accuracy range from $89.29 \%$ (barren rocky area) to $100 \%$ (water body, sandy area and waste land). Later, in the year 2015 producers' accuracy ranged from 85\% (water body) to 100\% (barren rocky area, sandy area and marshy land) and users' accuracy range from $91.30 \%$ (vegetation) to $100 \%$ (water body and sandy area). This error matrix is based on training data. If the results are good it indicates that the training samples are spectrally separable and the classification works well in the training areas.

\subsection{Kappa Coefficient}

Discrete multivariate techniques have been used to statistically evaluate the accuracy of remote sensing derived maps and error matrices since 1983 and are widely adopted. These techniques are appropriate as the remotely sensed data are discrete rather than continuous and are also binomially or multinomially distributed rather than normally distributed. Kappa analysis is a discrete multivariate technique for accuracy assessment. Kappa analysis yields a Khat statistic that is the measure of agreement of accuracy.

Table 3: KAPPA $\left(\mathrm{K}^{\wedge}\right)$ STATISTICS

\begin{tabular}{|l|c|c|c|}
\hline & \multicolumn{3}{|c|}{ Conditional Kappa for each Category } \\
\hline Class Name & $\mathbf{2 0 0 5}$ & $\mathbf{2 0 1 0}$ & $\mathbf{2 0 1 5}$ \\
\hline Water body & 1 & 1 & 1 \\
\hline Vegetation & 0.9069 & 0.9065 & 0.9090 \\
\hline Forest & 0.9157 & 0.9193 & 0.9637 \\
\hline Sandy Area & 0.0000 & 1 & 1 \\
\hline Barren Rocky Area & 0.8837 & 0.8807 & 0.9756 \\
\hline Marshy Land & 0.7980 & 0.8918 & 0.9265 \\
\hline Waste Land & 0.9747 & 1 & 0.9894 \\
\hline Overall Kappa Statistics & 0.9274 & 0.9446 & 0.9706 \\
\hline
\end{tabular}

The overall kappa statistics temporally varied from $0.9274,0.9446$ to 0.9706 in the respective years (Table 3). The khat statistics of the year 2015 shows the maximum agreement of accuracy. 


\section{Conclusion}

In the present study, spatio-temporal analysis was performed for Land use/cover for the years 2005 , 2010 and 2015 respectively. The Land use/cover was derived through supervised classification method. The area has been negatively affected due to establishment of power plants. Forest covers have been reduced and its impacts can be visualized on biodiversity characterization, which is a negative sign of environmental impact. Marshy area has increased due to the industrial activities such as discharge of effluents. Waste lands had been continuously increasing, due to increase in industrial activities and dumping of waste in open areas. From the present study, the influence of anthropogenic activities can be observed on land use/cover. Geo-spatial technology is an appropriate technology to analyze land use/cover mapping and change detection.

\section{References}

[1] A. J. Yunus, M., N. Nakagoshi, and A. L. Ibrahim, Application of GIS and remote sensing for measuring and evaluating land-use change and its impact on water quality in the Pinang River watershed, Ecology and Civil Engineering, 6, 2003, 97-110.

[2] B.S. Bisht, and B.P. Kothyari, Land-cover change analysis of Garur Ganga watershed using GIS / Remote sensing Technique. Journal. Indian society of Remote Sensing, 29 (3), 2001, 165-174.

[3] D. Card, Using known map category marginal frequencies to improve estimates of thematic map accuracy, Photogrammetric Engineering and Remote Sensing, 48(3), 1982, 431-439.

[4] D.S. Wilkie, and J.T. Finn, Remote Sensing Imagery for Natural Resources_Monitoring, (Columbia University Press, New York 1996) 295.

[5] E. Lopez, G. Bocco, M. Mendoza, and E. Duhau, Predicting land-cover and land-use change in the urban fringe: a case in Morelia city, Mexico, Landscape Urban Planning, 55, 2001, 271-285.

[6] F. Alonso-Perez, A. Ruiz-Luna, J. Turner, C. A. Berlanga-Robles and G. G. Mitchelson-Jacob, Land cover changes and impact of shrimp aquaculture on the landscape in the Ceuta coastal lagoon system, Sinaloa, Mexico, Ocean Coast. Management. 46, 2003, 583-600.

[7] J. Chilar, Land cover mapping of large areas from satellites: status and research priorities, International Journal of Remote Sensing, 21(67), 2000, 1093-1114.

[8] J. Cohen, A coefficient of agreement for nominal scales, Educational and Psychological Measurement, Vol. 20, No. 1,1960, 37-40.

[9] J. L. Star, J. E. Estes and K.C. McGwire, Integration of geographic information systems and remote sensing, (New York, NY: Cambridge University Press 1997).

[10] Jensen, J.R., Digital Image Processing, an Introductionary Perspective. (Prentice-Hall: Englewood Cliffs, N.J, 1986).

[11] R. Congalton, A Review of Assessing the Accuracy of Classifications of Remotely Sensed Data. Remote Sensing of Environment, 37, 1991, 35-46.

[12] R. Congalton, R. Oderwald, and R. Mead, Assessing Landsat classification accuracy using discrete multivariate statistical techniques, Photogrammetric Engineering and Remote Sensing, 49(12), 1983, 1671-1678.

[13] S. Tharimena, H. Gampwar, and Y.B. Katpatal, Environmental Impact assessment (EIA), based studies of thermal power plant on the hydrologic Regime using Remote Sensing, Paper presented at Geospatial World Forum, Hyderabad, India,18-21 January 2011.

[14] T. V. Ramachandra, and H. A. Bharath, Land use dynamics at Padubidri, Udupi District with the implementation of large scale thermal power project, International journal of Earth Sciences and Engineering, 5, 2012, 409-417.

[15] T.S. Kachhwala, Temporal monitoring of forest land for change detection and forest cover mapping through satellite remote sensing, Proc. 6th Asian Conference on Remote Sensing. Hyderabad, India, 1985, 77-83.

[16] Y. Dong, B. Forster, and C. Ticehurst, Radar backscatter analysis for urban environments. International Journal of Remote Sensing, 18(6), 1997, 1351-1364. 